\title{
Comparative Corrosion and Current Burst Testing of Copper and Aluminum Electrical Power Connectors
}

\author{
Ron Frank, Eng., Member, IEEE \\ Canadian Copper and Brass Association \\ Don Mills, Ontario, Canada
}

\author{
Chris Morton, P.Eng., Member, IEEE \\ Powertech Labs Inc. \\ Surrey, B.C., Canada
}

\begin{abstract}
Crimped and mechanically bolted aluminum and copper connectors are commonly used for terminating industrial electrical power cables with ratings up to $600 \mathrm{~V}$. Aluminum connectors are available for use with aluminum or copper conductor, and copper connectors are available for use with copper conductor only. The performance of copper and aluminum connectors was compared by conducting accelerated aging under corrosive environmental conditions. The testing consisted of 2000 hours of cyclic salt fog environmental exposure, in conjunction with periodic electrical current burst testing. The connectors were evaluated by comparing the change in resistance of the test samples as the test progressed.
\end{abstract}

Keywords-Electrical Connector; Aluminum Connector; Copper Connector; Corrosion Testing; Contact Resistance

\section{INTRODUCTION}

For industrial and commercial applications, crimped and mechanically bolted aluminum and copper connectors are commonly used for terminating power cables. Copper connectors are available for use with copper conductor, and aluminum connectors are available for use with copper and aluminum conductor. Test standards for power connectors include CSA C57 and ANSI C119.4 500-cycle current cycling tests, which are intended to establish long-term performance. There are significant differences in the material and electrical properties of aluminum and copper and their oxides, which may affect their long-term performance.

Aluminum oxidizes readily when exposed to air, and a strongly attached, hard outer layer of electrically insulating oxide quickly forms around the metal. For this reason, aluminum connectors are usually manufactured with a tin coating, which is intended to prevent surface oxidation of the connector from occurring. Aluminum crimp connectors are also pre-filled with oxide inhibiting compound to reduce oxidation between the conductor and connector when in service. Aluminum conductors must always be wire brushed to remove the oxide layer, and oxide inhibiting compound is immediately applied to reduce oxidation.

Copper also oxidizes when exposed to air, but the oxide which forms is relatively soft and conductive, although not as conductive as the base metal. For this reason, copper connectors can often be installed without oxide inhibitor. Wire brushing of the conductor, although recommended, is not as critical as with aluminum. Copper connectors are often manufactured with a tin coating to reduce surface oxidation and discolouration, but they are also available without tin coating.

This work was requested and funded by the Canadian Copper and Brass

Development Association (CCBDA) in Toronto, Ontario.
When copper and aluminum are brought into direct contact in the presence of moisture, a strong galvanic reaction takes place due to the dissimilar properties of the metals. For this reason, aluminum connectors are not used with copper conductor unless an interface material that is more compatible with both copper and aluminum is present, such as tin. However, tin is also susceptible to oxidation, and if the tin layer is compromised then galvanic corrosion between the base metals can still occur.

The differences in properties of copper and aluminum may result in a significant performance difference in the various types of electrical connectors when in long-term service.

\section{OBJECTIVE}

The objective of this study was to compare the contact resistance at the junction between the connector and conductor under harsh environmental laboratory testing conditions for the following material combinations:

- copper connectors on copper conductor,

- aluminum connectors on copper conductor, and

- aluminum connectors on aluminum conductor.

The connectors, conductor, and oxide inhibitor used to make the samples were standard commercially available varieties obtained from several different manufacturers. Manufacturer names are omitted from this paper since the intention of the study was not to compare specific manufacturer's products. A variety of commonly available products were used so that general conclusions could be drawn.

\section{TEST SAMPLES}

The test samples used in the study were combinations of copper and aluminum conductors and connectors, with all components being standard off-the-shelf varieties. Copper conductor was bare 19-strand 2/0 AWG, and aluminum conductor was 18-strand compact 4/0 AWG. Conductor sizes were selected to be approximately the same ampacity. Connectors were a combination of compression and mechanical bolted type 1-hole lug connectors, with a total of ten connectors of each material combination used. All aluminum compression connectors were tin plated and supplied pre-filled with oxide inhibitor. A list of the test samples is provided in Table I, and a photograph of the samples as received is shown in Fig. 1. 
TABLE I. CONNECTOR SAMPLES USED FOR THE TESTING

\begin{tabular}{|c|c|c|c|c|c|c|}
\hline \multirow[b]{2}{*}{$\begin{array}{l}\text { Sample } \\
\text { Nos. }\end{array}$} & \multirow{2}{*}{$\begin{array}{c}\text { Connec- } \\
\text { tor } \\
\text { Mate- } \\
\text { rial }\end{array}$} & \multirow{2}{*}{$\begin{array}{c}\text { Conduc } \\
\text {-tor } \\
\text { Mate- } \\
\text { rial }\end{array}$} & \multicolumn{4}{|c|}{ Connector Information } \\
\hline & & & Type $^{a}$ & $\begin{array}{l}\text { Manu- } \\
\text { facturer }\end{array}$ & $\begin{array}{c}\text { Size } \\
\text { (AWG } \\
\text { or } \\
M C M)\end{array}$ & Plating \\
\hline $\mathrm{A} 1, \mathrm{~A} 2$ & $\mathrm{Al}$ & $\mathrm{Al}$ & Mech. & A & $\# 6-250$ & Tin \\
\hline $\mathrm{A} 3, \mathrm{~A} 4$ & $\mathrm{Al}$ & $\mathrm{Al}$ & Comp. & A & $4 / 0$ & Tin \\
\hline A5, A6 & $\mathrm{Al}$ & $\mathrm{Al}$ & Comp. & B & $4 / 0$ & Tin \\
\hline $\mathrm{A} 7, \mathrm{~A} 8$ & $\mathrm{Al}$ & $\mathrm{Al}$ & Mech. & $\mathrm{C}$ & $\# 6-250$ & Tin \\
\hline A9, A10 & $\mathrm{Al}$ & $\mathrm{Al}$ & Comp. & D & $4 / 0$ & Tin \\
\hline $\mathrm{B} 1, \mathrm{~B} 2$ & $\mathrm{Al}$ & $\mathrm{Cu}$ & Comp. & $\mathrm{D}$ & $2 / 0$ & Tin \\
\hline B3, B4 & $\mathrm{Al}$ & $\mathrm{Cu}$ & Comp. & $\mathrm{C}$ & $2 / 0$ & Tin \\
\hline B5, B6 & $\mathrm{Al}$ & $\mathrm{Cu}$ & Comp. & A & $2 / 0$ & Tin \\
\hline B7, B8 & $\mathrm{Al}$ & $\mathrm{Cu}$ & Mech. & $\mathrm{C}$ & $\# 6-250$ & Tin \\
\hline B9, B10 & $\mathrm{Al}$ & $\mathrm{Cu}$ & Mech. & A & \#6-250 & Tin \\
\hline $\mathrm{C} 1, \mathrm{C} 2$ & $\mathrm{Cu}$ & $\mathrm{Cu}$ & Comp. & $\mathrm{D}$ & $2 / 0$ & Tin \\
\hline $\mathrm{C} 3, \mathrm{C} 4$ & $\mathrm{Cu}$ & $\mathrm{Cu}$ & Comp. & $\mathrm{C}$ & $2 / 0$ & Tin \\
\hline $\mathrm{C} 5, \mathrm{C} 6$ & $\mathrm{Cu}$ & $\mathrm{Cu}$ & Comp. & A & $2 / 0$ & Tin \\
\hline $\mathrm{C} 7, \mathrm{C} 8$ & $\mathrm{Cu}$ & $\mathrm{Cu}$ & Mech. & $\mathrm{C}$ & $\# 6-250$ & None \\
\hline $\mathrm{C} 9, \mathrm{C} 10$ & $\mathrm{Cu}$ & $\mathrm{Cu}$ & Mech. & A & $\# 2-4 / 0$ & None \\
\hline
\end{tabular}

a. Mech. $=$ mechanical, Comp.$=$ compression

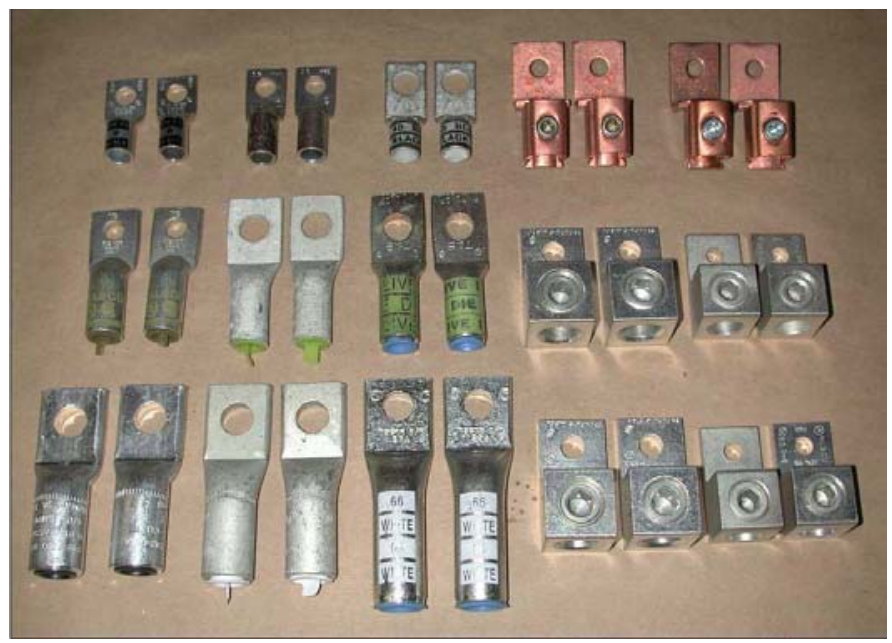

Figure 1. Connector samples used for corrosion and current burst testing.

\section{A. Connector Installation Procedures}

Connectors were installed according to the manufacturer's recommendations. This included wire brushing the conductor, applying an off-the-shelf oxide inhibitor (for aluminum mechanical connectors only), and crimping of the compression connectors using a standard manual crimping tool. No oxide inhibitor was applied to any of the copper-to-copper connections. Mechanical connectors were installed using torque levels appropriate to the screw size in the clamping mechanism of the connector.

\section{B. Connector Sample Assemblies}

Each connector sample was installed on approximately $0.5 \mathrm{~m}$ of conductor, with a current equalizer on the end of the conductor opposite each connector. The equalizer was intended to provide a solid electrical connection to each strand of the conductor, so that current could be applied uniformly to the conductor. Welded aluminum equalizers were used on the aluminum conductor, and brazed copper equalizers were used on the copper conductor. Three groups of 10 samples each were connected together back-to-back to form three series circuits, which were labeled as sample sets 'A' (all aluminum), ' $\mathrm{B}$ ' (copper conductor with aluminum connectors), and ' $\mathrm{C}$ ' (all copper). A photograph of a complete connector assembly, with 10 connectors and equalizers, is shown in Fig. 2. Control conductors were subjected to the corrosion and current burst testing along with the connector and conductor samples. These consisted of $1 \mathrm{~m}$ lengths of copper and aluminum bare conductor with no connector attached.

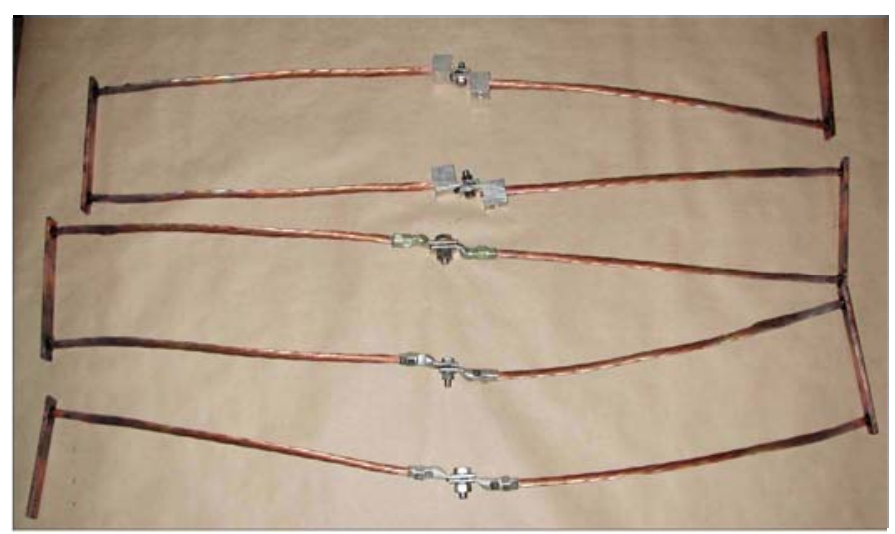

Figure 2. Connector sample assembly with equalizers and conductor (copper conductor with aluminum connector samples shown).

\section{TEST Procedures}

The testing consisted of periods of corrosive environmental exposure, followed by application of high current. This was intended to produce conditions in which connectors that were susceptible to corrosion showed an increase in contact resistance as the testing progressed.

The cyclic testing was conducted in the following sequence:

- Salt fog corrosion cycling was carried out for 500 hour blocks of time.

- Current burst tests were carried out following each 500 hour salt fog period.

- DC resistance readings of each connector were made approximately every 170 hours during the corrosion testing, and before and after each set of current burst tests.

- A total of four sets of salt fog and current burst tests were conducted, for a total of approximately 2000 hours of salt fog testing. 


\section{A. Corrosion Cycling}

Connector sample groups were arranged on a three-tier PVC rack in an environmental chamber with the conductors and connectors oriented horizontally, and the connectors suspended in clear air. The positions of the connector sets were exchanged periodically so that consistent environmental exposure from sample to sample was achieved over the testing period.

Each 4 hour corrosion testing cycle consisted of the following steps:

- Salt fog spray for a period of 1 hour 45 minutes, consisting of a fine mist of aerated $3 \% \mathrm{NaCl}$ solution buffered to a $\mathrm{pH}$ of 5.5 using nitric acid.

- Dry heat for a period of 2 hours, reaching a maximum of $70^{\circ} \mathrm{C}$ during the 2 hour period.

- Clear water rinse for a period of 15 minutes.

\section{B. Current Burst Testing}

The reason for conducting current burst testing was to encourage accelerated degradation at the connector contact with the conductor. For the test, current levels of 1750 Arms for 4/0 aluminum conductor, and 1800 Arms for $2 / 0$ copper conductor were determined to be sufficient to produce the desired effect. For each test, the current was held at the required level long enough to raise the temperature of the control conductor to $250^{\circ} \mathrm{C}$, as determined by a thermocouple measurement at the center of the control conductor span. Typically, this required an application of current for approximately 50 seconds, starting with a conductor at near room temperature. The calculation to determine these levels is described in detail in Appendix A.

Samples were subjected to current burst testing as follows:

- Each set of 10 connectors, which were joined together in series, were subjected to current burst testing simultaneously.

- The control conductor was placed in series with the connector assembly. A thermocouple was attached to the center of the length of each control conductor to measure the conductor temperature during current burst testing.

- Five short duration bursts of high current were applied in succession. The control sample was allowed to cool to $40^{\circ} \mathrm{C}$ or less between each current burst.

The contact resistance of each connector was measured at room temperature using a micro-ohmmeter before and after each set of five current burst tests.

\section{DC Resistance Measurements}

All contact resistances were measured on dry samples at room temperature $\left(20^{\circ} \mathrm{C}\right)$ using a LEM model D3700 microohmmeter. Since resistances were all measured at the same temperature level, no correction was applied.
Resistances were measured from the equalizer to the body of the connector, so that an average reading was obtained for each connector. Four point resistance measurements were made to eliminate lead resistance errors, and measurements were made at a current level of 10 A DC.

\section{TEST Results}

\section{A. Resistance Measurements}

1) Raw Test Data: Bar charts showing all of the measured resistances during the testing are shown in Fig. 3 through Fig. 5. The resistance values are displayed in chronological order from left to right, so that the left-most bar is the reading before testing, and the right-most bar is the reading after 2000 hours of environmental exposure and final current burst testing.

2) Aluminum Equalizer Failure and Corrected Results: During the last set of current burst tests (after 2000 hours of corrosion cycling), a problem with the welded aluminum equalizers became apparent when one of the equalizers, on sample no. A7, was damaged by excessive heating during the first current shot. It appeared that some of the welded aluminum equalizers were being excessively degraded by the environmental exposure.

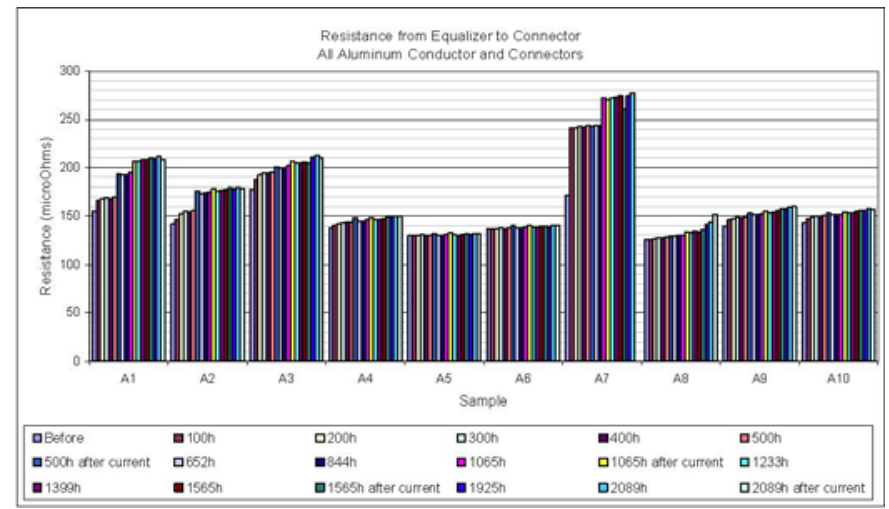

Figure 3. Resistance measurements for all-aluminum connections (Group A).

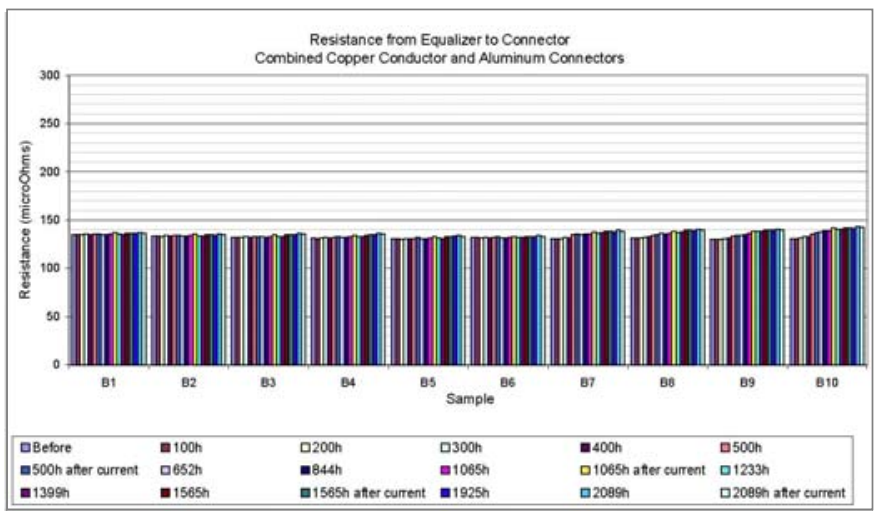

Figure 4. Resistance measurements for aluminum connectors on copper conductor (Group B). 


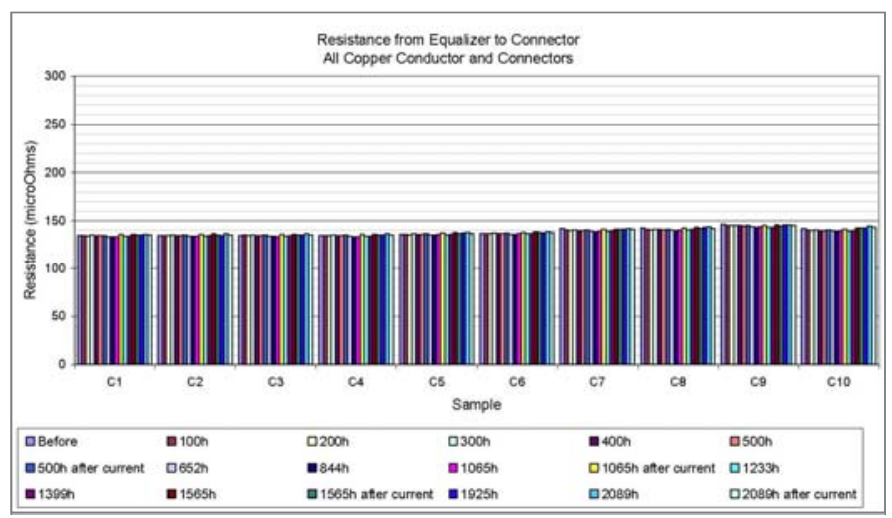

Figure 5. Resistance measurements for all-copper connections (Group C).

A current distribution measurement was necessary to confirm which equalizers had probably sustained damage. The current distribution was determined by measuring the voltage drop over a fixed distance on each of the 11 outer strands with a fixed DC current of $10 \mathrm{~A}$ applied to the entire conductor from equalizer to connector. The equalizers with a small variation between voltage readings were assumed to have had an evenly distributed current, which indicated that the equalizer and connector were still making a consistent connection. The equalizer/connector groups with a large variation in voltage had either a poor connection at the equalizer, a poor connection at the connector, or both. A graph of the measured voltage values, which have been normalized to the average reading for each equalizer, is shown in Fig. 6. The results indicated that samples A1, A3, A7, A8, and A10 had a poor current distribution, and were suspected of being damaged. For these samples, the old equalizer was cut off, the conductor was thoroughly cleaned and wire brushed, and a new equalized connection was made using a new aluminum compression connector. The equalizer-to-connector resistances were then re-measured for these samples, and a small correction was made to compensate for the amount of conductor that was cut off. The new values were used as the final resistance readings. A graph with the corrected measured resistances of the aluminum connectors with re-made equalizers are shown in Fig. 7. For the connectors with re-made equalizers, since the only valid readings were made at the beginning and end of the test, all other readings were omitted.

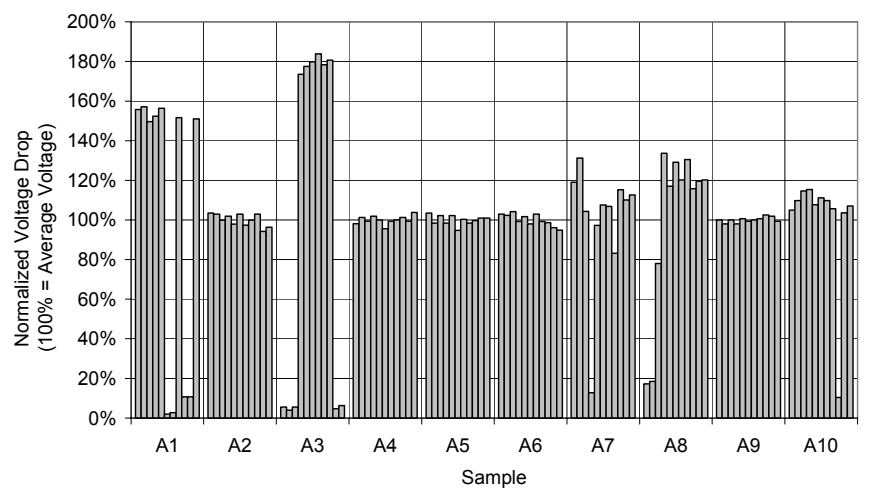

Figure 6. Current distribution measured by voltage drop along the conductor outer strands. Results were normalized to the average voltage for each equalizer.

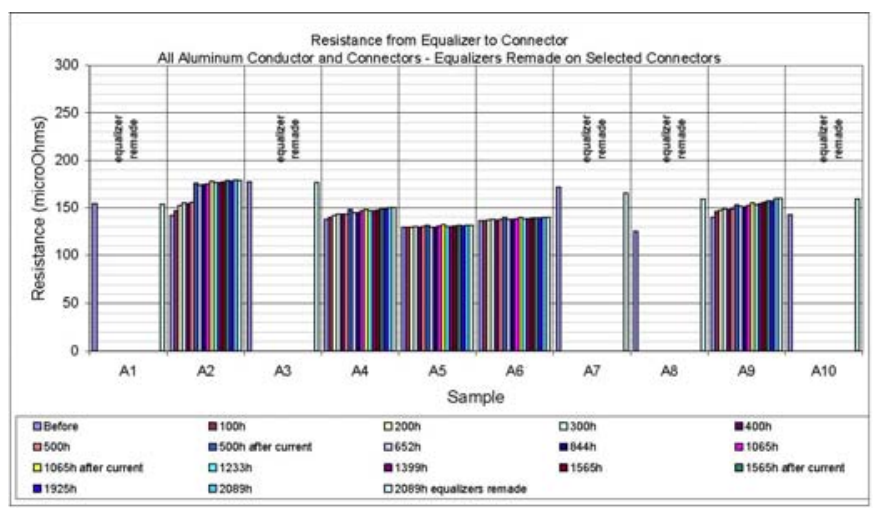

Figure 7. Corrected resistance measurements for all-aluminum connections (Group A).

\section{B. Connector Appearance}

1) Aluminum Connectors: The aluminum connectors on both the aluminum and copper conductor showed a considerable amount of surface corrosion after testing, and a build-up of white oxidation. On some of the mechanical connectors, the tin plating had flaked off the surface and the underlying aluminum showed signs of corrosion. Photographs of the all-aluminum connectors before and after testing are shown in Fig. 8, and the aluminum connectors on copper conductor are shown in Fig. 9.

2) Copper Connectors: The copper connectors had a duller finish after the testing and showed some signs of surface oxidation, but the tin plating was intact (where present). Photographs of the all-copper connections before and after testing are shown in Fig. 10.

\section{DISCUSSION}

The measured resistance values are made up of a combination of the equalizer resistance, conductor resistance, and connector contact resistance. Since the conductor resistance dominates, even significant changes in the connector contact resistance may not result in a large change in the overall resistance reading. By calculating the resistance readings during the testing as a percentage of the initial resistance reading, the overall effect can be more easily seen. Fig. 11 shows the percent change in resistance for all connectors, measured after each current burst test.

On average, the before-test equalizer-to-connector resistance readings were approximately $145 \mu \Omega$ for the aluminum conductor samples, and $135 \mu \Omega$ for the copper conductor samples. Initial contact resistance readings from the conductor to the connector were measured at approximately $10-15 \mu \Omega$, or approximately $10 \%$ of the total resistance reading. Assuming that most of the change in resistance during the test is due to an increase in connector contact resistance, then an increase in equalizer-to-connector resistance of $10 \%$ would correspond to an increase in connector contact resistance of over $100 \%$. On this basis, an increase in the equalizer-toconnector resistance of $5 \%$ may be considered to be significant, and an increase of $10 \%$ or more may be considered to be a failure of the connector. 


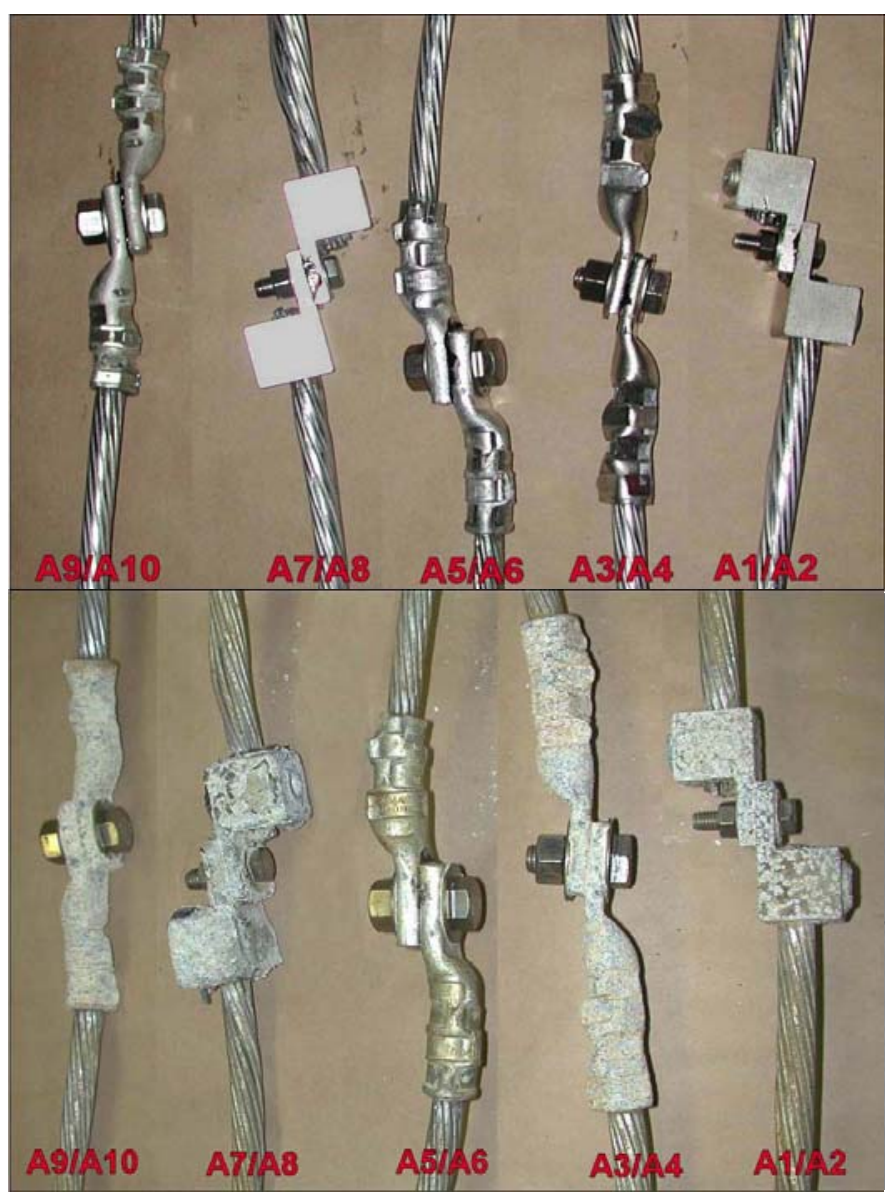

Figure 8. All-aluminum connections before testing (top) and after 2000 hours of environmental testing (bottom).

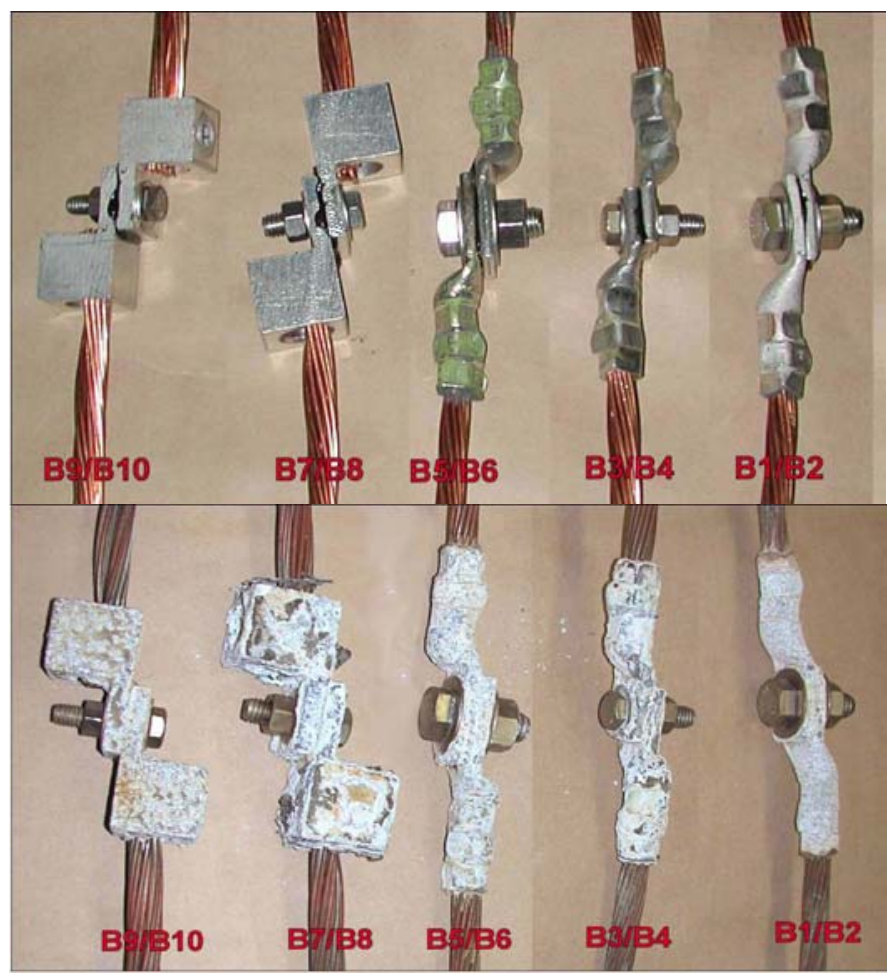

Figure 9. Aluminum connectors on copper conductor before testing (top) and after 2000 hours of environmental testing (bottom).

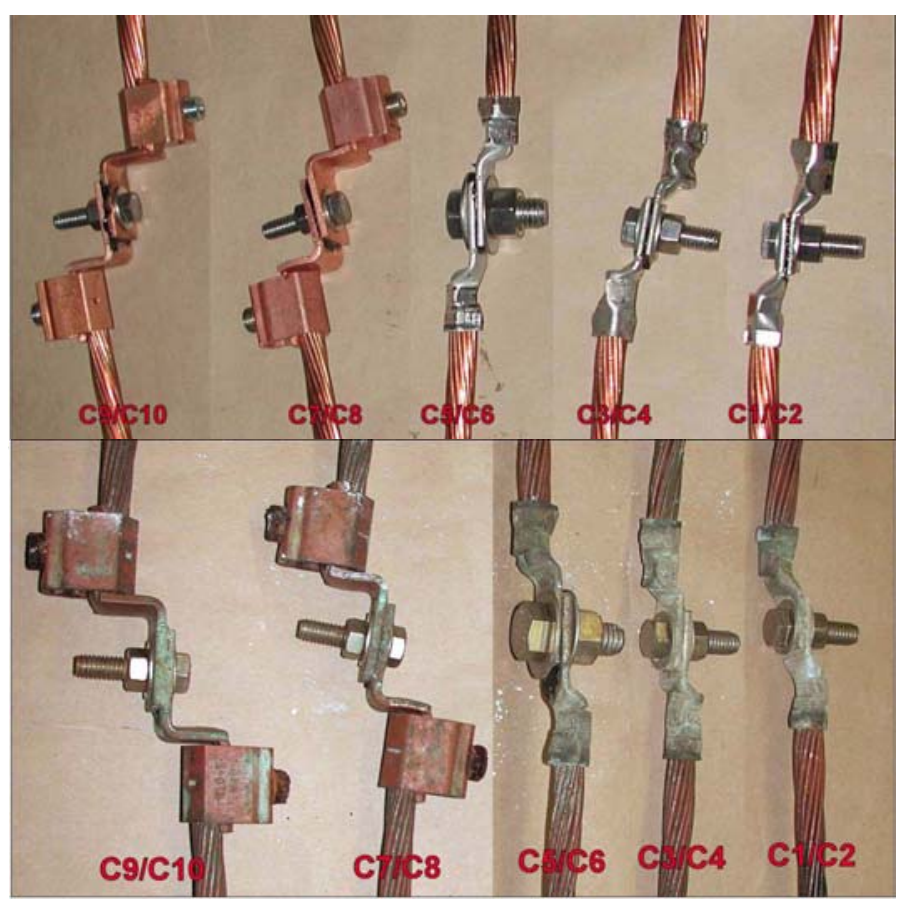

Figure 10. All-copper connections before testing (top) and after 2000 hours of environmental testing (bottom).

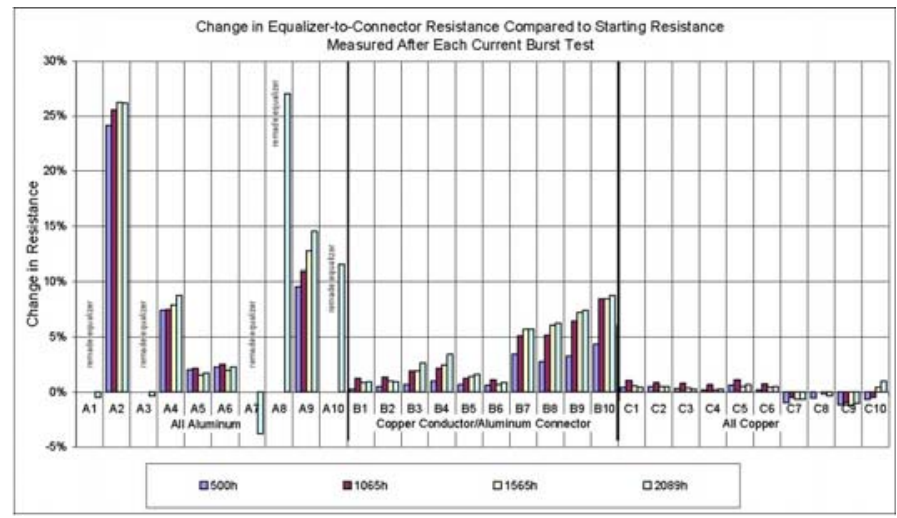

Figure 11. Percent change in resistance for all connectors compared to the resistance before testing, measured after each set of current burst tests.

The final results of the corrosion and current burst testing are given in Table II, which shows the number of samples of each type listed by percent change in resistance over the entire testing period.

TABLE II. Number Of SAMPLES Of EACH TyPe Listed By Percent Change In Resistance DuRING The TeSt

\begin{tabular}{|c|c|c|c|c|c|c|}
\hline \multirow[b]{2}{*}{$\begin{array}{l}\text { Connector } \\
\text { Type }\end{array}$} & \multirow[b]{2}{*}{$\begin{array}{l}\text { Conductor } \\
\text { Type }\end{array}$} & \multicolumn{5}{|c|}{$\begin{array}{c}\text { Overall resistance change compared to } \\
\text { starting resistance: }\end{array}$} \\
\hline & & $\begin{array}{c}-5 \% \\
\text { to } \\
0 \%\end{array}$ & $\begin{array}{c}0 \% \\
\text { to } \\
+1 \%\end{array}$ & $\begin{array}{r}+1 \\
\text { to } \\
+5 \%\end{array}$ & $\begin{array}{c}+5 \% \\
\text { to } \\
+10 \%\end{array}$ & $>+10 \%$ \\
\hline $\mathrm{Al}$ & $\mathrm{Al}$ & 3 & 0 & 2 & 1 & 4 \\
\hline $\mathrm{Al}$ & $\mathrm{Cu}$ & 0 & 3 & 3 & 4 & 0 \\
\hline $\mathrm{Cu}$ & $\mathrm{Cu}$ & 3 & 7 & 0 & 0 & 0 \\
\hline
\end{tabular}




\section{CONCLUSIONS}

The overall results for each connection type may be summarized as follows:

\section{A. Aluminum connectors on aluminum conductor:}

- $40 \%$ of the connector samples could be considered to have failed ( $>10 \%$ increase).

- $10 \%$ of the samples showed a significant increase in resistance (5\% to $10 \%$ increase).

- $20 \%$ of the samples showed a moderate increase in resistance ( $1 \%$ to $5 \%$ increase).

- $30 \%$ of the samples showed a decrease in resistance.

\section{B. Aluminum connectors on copper conductor:}

- $40 \%$ of the samples showed a significant increase in resistance (5\% to $10 \%$ increase).

- $30 \%$ of the samples showed a moderate increase in resistance ( $1 \%$ to $5 \%$ increase).

- $30 \%$ of the samples showed a decrease in resistance.

\section{Copper connectors on copper conductor:}

- $70 \%$ of the samples showed a small increase in resistance ( $0 \%$ to $1 \%$ increase).

- $30 \%$ of the samples showed a decrease in resistance.

The best performance in this 2000 hour corrosion and current burst test was attained by the all-copper connectors, which showed very little sign of degradation in electrical performance.

\section{APPENDIX A}

\section{DETERMINATION OF CURRENT BURST LEVEL}

A mechanical or compression high current connection relies on good asperity contact at the connection interface to maintain a low contact resistance. Asperity contact is maintained by the residual contact force on the connector, which is supplied by the screw fitting in a mechanical connector, or the residual stress in the deformed metal in a compression connector.

Under corrosive conditions, a poor connection may build up insulating oxides in the spaces between the asperities and at the edges of the asperities. High level, short duration current bursts are applied to the samples for sufficient duration to produce elevated temperatures at the asperity interface between the connector and conductor. The intention is to produce softening or melting of the asperities at the interface during the test. In a connector which has a build up of oxides, softening or melting at the asperities may cause loss of asperity contact if the residual force on the connector is insufficient to re-establish asperity contact with the oxide layer present. In an oxide free connection, the residual force can actually improve asperity contact when the asperities soften, resulting in a lower contact resistance.
The objective is to apply current bursts at a level which produces interface melting in a contact which has a high enough resistance to result in interface softening in the standard CSA C57 500-cycle connector test [4]. Therefore, the current pulse level is determined as follows.

According to Holm [2], the voltage drop across a contact is given by the following relation.

$$
\mathrm{U}_{\mathrm{p}}^{2}=4 \mathrm{~L}\left(\mathrm{~T}_{\mathrm{I}}^{2}-\mathrm{T}_{\mathrm{B}}^{2}\right)
$$

where:

$$
\begin{aligned}
& \mathrm{U}_{\mathrm{p}}=\text { peak voltage drop across contact } \\
& \mathrm{L}=\text { independent constant } 2.4 \times 10^{-8} \mathrm{~V}^{2} \mathrm{~K}^{-2} \\
& \mathrm{~T}_{\mathrm{I}}=\text { absolute temperature }(\mathrm{K}) \text { of the contact spots in the } \\
& \text { interface } \\
& \mathrm{T}_{\mathrm{B}}=\text { absolute temperature }(\mathrm{K}) \text { of the bulk of the connector }
\end{aligned}
$$

A bulk temperature of $100^{\circ} \mathrm{C}$ is used in the calculation, which is the maximum control conductor temperature used in the $\mathrm{C} 57$ cycling test. The RMS voltage, $\mathrm{U}_{\mathrm{rms}}$, is obtained by dividing the peak voltage by $\sqrt{ } 2$.

The magnitude of the current, I, required to produce either softening or melting at the interface is given by:

$$
\mathrm{I}=\mathrm{U}_{\mathrm{rms}} / \mathrm{R}
$$

where:

$\mathrm{R}=$ resistance at which either interface softening occurs in the $\mathrm{C} 57$ test, or melting occurs in the current burst test.

The current burst levels calculated are given in Table III. The calculation indicates that current levels of approximately $1800 \mathrm{~A}_{\mathrm{rms}}$ and $1750 \mathrm{~A}_{\mathrm{rms}}$ are suitable for copper and aluminum respectively.

TABle III. Calculated Current Burst Levels

\begin{tabular}{|c|c|c|c|c|c|c|c|c|}
\hline $\begin{array}{c}\text { Conduc- } \\
\text { tor } \\
\text { Size }\end{array}$ & $\begin{array}{c}\text { Conductor } \\
\text { Material }\end{array}$ & $\begin{array}{c}\text { Interface } \\
\text { Softening } \\
\text { Temperature } \\
\left({ }^{\circ} \mathbf{C}\right)\end{array}$ & $\begin{array}{c}\text { Interface } \\
\text { Melting } \\
\text { Temperature } \\
\left({ }^{\mathbf{C}} \mathbf{C}\right)\end{array}$ & $\begin{array}{c}\text { Softening } \\
\text { Voltage } \\
\mathbf{U}_{\text {rms }}^{\mathbf{a}} \\
(\mathbf{m V})\end{array}$ & $\begin{array}{c}\text { Melting } \\
\text { Voltage } \\
\mathbf{U}_{\text {rms }}^{\mathbf{a}} \\
(\mathbf{m V})\end{array}$ & $\begin{array}{c}\text { CSA C57 } \\
\mathbf{C u r r e n t} \\
\mathbf{( A )}\end{array}$ & $\begin{array}{c}\text { Softening } \\
\text { or Melting } \\
\text { Contact } \\
\text { Resistance } \\
(\mathbf{m} \boldsymbol{\Omega})\end{array}$ & $\begin{array}{c}\text { Current } \\
\text { Burst } \\
\text { Level } \\
(\mathbf{A})\end{array}$ \\
\hline $2 / 0$ & $\mathrm{Cu}$ & 190 & 1083 & 60.1 & 286 & 380 & 0.158 & 1806 \\
\hline $4 / 0$ & $\mathrm{Al}$ & 150 & 660 & 43.7 & 187 & 408 & 0.107 & 1749 \\
\hline
\end{tabular}

a. Using a bulk temperature of $100^{\circ} \mathrm{C}$ from CSA C57.

b. From Table 6 and Table 8 from CSA C57.

\section{REFERENCES}

[1] T.L. McKoon, Georgia Power Project Report C94925, "Comparison of conductor performance", August 1995, p. 6.

[2] Holm, Ragnar, "Electric contacts", Fourth Edition, Springer-Verlag Berlin Heidelberg New York, 1967, pp. 60-64.

[3] V.L. Buchholz, Powertech Project 1895-23-03, “A Short Term Power Connector Test to Replace the Current Cycle Testing of CSA Standard C57-1966", November 1991.

[4] CSA C57-98, "Electric Power Connectors for Use in Overhead Line Conductors", March 1998. 